\title{
Views and Experiences of Overweight and Obese Adults on the Barriers and Facilitators to Weight Loss in Southeast Brazil: A Qualitative Study
}

Caroline Morgan ( $\nabla$ carolineimorgan@hotmail.com )

University of Birmingham College of Medical and Dental Sciences https://orcid.org/0000-0002-6307-1987

Gilles de Wildt

University of Birmingham College of Medical and Dental Sciences

Marcos Virmond

Instituto Lauro de Souza Lima

\section{Ruth Riley}

University of Birmingham

Nisha Thanikachalam

University of Birmingham College of Medical and Dental Sciences

Renata Billion Ruiz Prado

Instituto Lauro de Souza Lima

Research article

Keywords: Barriers, Brazil, facilitators, obesity, qualitative, weight loss

Posted Date: January 16th, 2020

DOI: https://doi.org/10.21203/rs.2.21048/v1

License: (c) (i) This work is licensed under a Creative Commons Attribution 4.0 International License. Read Full License 


\section{Abstract}

Background

Brazil has seen a large increase in obesity with $54 \%$ of the Brazilian population being overweight, of which $20 \%$ is obese. Obesity is a major risk factor for non-communicable diseases such as cardiovascular disease: the leading cause of mortality in Brazil. Weight loss can reduce the health and economic burden of obesity-related diseases. Despite many weight loss strategies, the obesity rate in Brazil remains high. This study aims to identify the barriers and facilitators to weight loss as perceived by patients with a view to reducing the burden of obesity-related diseases on patients and healthcare services.

Methods

Fifteen qualitative, semi-structured, in-depth interviews were conducted with the primary researcher in the preventive medicine department in a private health clinic in Bauru, Sao Paulo State, Southeast Brazil. Inductive thematic analysis was conducted.

Results

Barriers and facilitators were classified into three key themes: lifestyle, motivation and education. Barriers included the expensive cost of a healthy lifestyle, junk food advertising, risks of outdoor exercise, time restrictions, poor mental health, sleep deprivation, medication side-effects, misinformation and lack of accessibility to weight loss treatment through the public healthcare system. Facilitators to weight loss included a change in eating habits, packed meals, documenting eating habits, motivation from consequences of obesity, acceptance of a lifelong commitment, support from social capital, psychologists in the multidisciplinary team, financial support and good quality education, particularly the use of expert patients as educators.

\section{Conclusion}

The study contributes to the existing literature on obesity in Brazil. Barriers to a healthy lifestyle such as financial difficulties, accessibility to treatment and junk food advertising need to be addressed. Education is vital to promote the facilitators and target these barriers and dispelling myths on weight loss. Expert patients should be utilised as an education method, as they increase motivation and provide realistic expectations of the weight loss process.

\section{Introduction}

Obesity is a growing problem globally, with 1.9 billion adults in the world being overweight, of which 650 million are obese (1). In Brazil, $54.2 \%$ of the population is overweight, of which $20.1 \%$ is obese (2). The obesity rate increased by $50 \%$ between 2006 and 2012 and it is predicted that by 2022, almost two-thirds of the population will be overweight and a quarter obese (3). Brazil performs the second highest number of bariatric surgeries $(0.04334 \%$ of the total population) following the USA $(0.044 \%$ of the total population) $(4,5)$. In comparison, the rate of bariatric surgeries in the UK population is $0.0087 \%(5)$. The rise in prevalence of obesity is attributed to cheap high caloric foods, increased prices on nutritious foods, physical inactivity and stress (6).

The World Health Organisation (WHO) defines overweight as a Body Mass Index (BMI) greater than $25 \mathrm{~kg} / \mathrm{m}^{2}$, and obesity is greater than $30 \mathrm{~kg} / \mathrm{m}^{2}$ (7). Obesity is a major risk factor for non-communicable diseases (NCDs) such as cardiovascular disease, non-insulin dependent diabetes mellitus, musculoskeletal disease and cancer (8). NCDs cause 74\% of deaths in Brazil, with cardiovascular disease being the top cause of mortality for the past 50 years $(9-11)$.

Obesity can severely impact patients psychologically, including body image dissatisfaction, low mood and self-esteem. The media presents negative messages about obesity which results in anti-fat bias causing stigma and discrimination, for example in education, employment, health and social settings (12). Additionally, an increased concern for body image in Brazil may be attributed to the hot climate and many beaches encouraging the population to wear body-exposing light clothing, therefore causing increased body image dissatisfaction $(13,14)$. 
Weight loss can improve cardiovascular risk factors such as hypertension, type 2 diabetes mellitus and metabolic syndrome, with clinically significant weight loss ( $>5 \%$ of baseline body weight) being most effective in reducing cardiovascular disease and type 2 diabetes mellitus risk factors $(15,16)$. Weight loss can also reduce the economic burden of obesity and obesityrelated diseases which currently costs $2.4 \%$ of GDP in Brazil (17). An estimation of US\$330 billion will be spent on obesity between 2010 and 2050; however, US\$27 billion can be saved within the 40 years if the obesity rate decreases by 1\% (18).

There are many strategies for weight loss, including reduced-calorie diets regardless of macronutrient composition which appears to be the most important factor for weight loss (19-21). Public health recommendations on physical activity have shown to be only effective with caloric restriction, however high volume aerobic exercise achieves clinically significant weight loss without caloric restriction (22-24). Pharmacotherapy has proven to be an effective method for weight loss (25). Weight loss surgery is also an effective method of weight loss after failure of lifestyle changes or pharmacotherapy and is associated with an improved quality of life and health (26-28). A multidisciplinary approach to weight loss has shown to be more effective than an individual physician approach (29).

Despite the many weight loss strategies implemented in Brazil, obesity rates remain high (30). Factors affecting adherence to weight loss in adults in Northeast Brazil have been explored (31). However, no study to date has explored patients' perspectives on the barriers and facilitators to weight loss in Southeast Brazil which is socioeconomically different and more obese than the Northeast (32-34).

The study aims to identify the barriers and facilitators to weight loss perceived by patients to address any changes required to reduce the obesity rates and burden of NCDs on patient health and healthcare services.

\section{Methods}

Study design and sampling

This was a qualitative study in the preventive medicine department of a private health clinic providing weight counselling in the city of Bauru, Sao Paulo State, Southeast Brazil. The data was collected over 4 weeks in February 2019. The setting at a specialist weight counselling clinic allowed for purposive sampling to be conducted, recruiting information-rich participants with experience of the barriers and facilitators to weight loss.

Participants and Recruitment

Participants were required to meet the inclusion criteria to participate in the study. Inclusion criteria were patients: registered at the health centre, over the age of 18 , males and females, BMI greater than $25 \mathrm{~kg} / \mathrm{m}^{2}$, able to give informed consent, able to speak Portuguese or English fluently. Exclusion criteria was impaired cognition.

Eligible participants were identified by the nutritionist, psychologist, doctor or nurse during weight counselling consultations at the health clinic. Interested participants met $\mathrm{CM}$ (primary researcher) who explained the study using the participant information sheet. The reason for patients' refusal to participate in the study was their lack of time to conduct the interviews.

\section{Ethical considerations}

The research was approved by the BMedSc Population Sciences and Humanities Internal Ethics Review Committee at the University of Birmingham, Scientific Committee and Ethics Committee at Instituto Lauro de Souza Lima. All participants signed an informed consent form before the interviews. Data were stored according to the University of Birmingham data protection policy (35).

Data collection

Data were collected using in-depth semi-structured interviews. The interviews were conducted in Brazilian Portuguese and English using real-time interpretation between the primary researcher, interpreter and participant. CM is female and conducted 
the interviews and took field notes, with the presence of an interpreter to translate the interviews from Brazilian Portuguese into English. The interpreters were MV (male) and RP (female) who are researchers involved in the study and the third interpreter was another researcher (female) at Instituto Lauro de Souza Lima. CM briefed the interpreters about the aims of the study, the importance of open questions, any issues from previous interviews and the interpreters practised asking the interview questions to minimise any inconsistencies in data collection. The use of an interpreter allowed for the primary researcher to have more control over data collection and flexibility in follow-up questions. An iterative approach was used to allow the inclusion of novel ideas until data saturation was achieved.

The interviews were conducted following a semi-structured topic guide (Table 1) developed from the aims of the study and review of previous qualitative studies $(31,36)$. The use of open questions allowed for flexibility in answers and closed questions for further clarification and in-depth exploration. A pilot phase was conducted on the first day of interviews, and following feedback from the participants and discussion between the researchers, minor adjustments to the demographic form and probing questions in the topic guide were made.

Table 1

Interview topic guide

\begin{tabular}{|ll|}
\hline Topic & Question \\
\hline Beliefs & What is your understanding of obesity? \\
\cline { 2 - 2 } & What is your view on being obese? \\
\cline { 2 - 2 } & Are there any advantages or disadvantages to obesity? \\
\hline Weight loss & What is your experience with weight loss? \\
\cline { 2 - 3 } & What do you know about weight loss? \\
\cline { 2 - 2 } & What are the barriers to weight loss? \\
\hline Future steps & What are the facilitators to weight loss? \\
\hline
\end{tabular}

The interviews were audio-recorded and the spoken Brazilian Portuguese was transcribed and translated into English by independent interpreters who were three local university students training to be professional interpreters. The English transcripts were revised by a second interpreter to ensure accurate English interpretation. The cultural context and colloquialisms were described in note form by the interpreters. Minimal discrepancies in interpretation were noted and therefore minimal changes were made following discussion with the interpreters.

The average length of the interviews was 27 minutes. The interviews were conducted in the same private consultation room at the health clinic to ensure consistency in the environment for all interviews.

\section{Data analysis}

Data was analysed using inductive, semantic thematic analysis, meaning themes were developed from the explicit meanings from the data. The analysis was conducted following Braun and Clarke's six steps for thematic analysis (37). This allowed for flexibility in the analysis and theme development. Immersion of the data was done through repeated reading of the entire data set. Initial coding and theme generation was conducted by CM, using support from the NVivo 12 software. Thematic mind maps were created, and themes were reviewed and refined in two cycles: first cycle by reading quotes from the data and the second cycle by reading the entire data set to ensure the themes accurately described the data.

To ensure credibility of analysis, a second qualitative researcher (NT) independently coded five of the most data-rich transcripts. Similarities and differences were noted and any differences were discussed between the researchers until a consensus was reached. A reflexive approach to analysis was used, where notes were made throughout the analytical process to assess the 
potential impact of researcher bias. The study was reported using the 'Consolidated criteria for reporting qualitative research (COREQ)' checklist (38).

\section{Results}

Participants

A total of 15 patients participated in the study. 12 of the participants were female and 3 were male. The average age was 43 years and the average BMI was $37.4 \mathrm{~kg} / \mathrm{m}^{2}$. The demographic information is summarised in Table 2.

Table 2

Demographic information of the participants

\begin{tabular}{|c|c|c|c|c|c|c|c|c|c|}
\hline $\begin{array}{l}\text { Participant } \\
\text { ID }\end{array}$ & Sex & $\begin{array}{l}\text { Age } \\
\text { range } \\
\text { (years) }\end{array}$ & $\begin{array}{l}\text { Body } \\
\text { Mass } \\
\text { Index } \\
\left(\mathrm{kg} / \mathrm{m}^{2}\right)\end{array}$ & Ethnicity & $\begin{array}{l}\text { Other } \\
\text { health } \\
\text { conditions }\end{array}$ & $\begin{array}{l}\text { Highest } \\
\text { level of } \\
\text { education }\end{array}$ & $\begin{array}{l}\text { Monthly } \\
\text { household } \\
\text { income } \\
\text { (US\$) }\end{array}$ & Employed & $\begin{array}{l}\text { Marital } \\
\text { status }\end{array}$ \\
\hline P1 & Female & $30-39$ & 44.5 & White & No & University & $790-1,300$ & Yes & Cohabiting \\
\hline P2 & Female & $30-39$ & 38.9 & Black & Yes & $\begin{array}{l}\text { High } \\
\text { School }\end{array}$ & $530-789$ & Yes & Married \\
\hline P3 & Female & $40-49$ & 30.2 & Brown & Yes & $\begin{array}{l}\text { High } \\
\text { School }\end{array}$ & $<265$ & No & Married \\
\hline P4 & Male & $40-49$ & 35.8 & White & Yes & $\begin{array}{l}\text { High } \\
\text { school }\end{array}$ & $530-789$ & Yes & Married \\
\hline P5 & Female & $50-59$ & 37.3 & White & Yes & College & $530-789$ & No & Married \\
\hline P6 & Male & $30-39$ & 39.2 & Black & Yes & University & $790-1,300$ & Yes & Married \\
\hline P7 & Female & $30-39$ & 37.6 & White & No & $\begin{array}{l}\text { High } \\
\text { School }\end{array}$ & $530-789$ & Yes & Cohabiting \\
\hline P8 & Female & $40-49$ & 25.2 & White & Yes & $\begin{array}{l}\text { Post- } \\
\text { graduate }\end{array}$ & $530-789$ & Yes & Married \\
\hline P9 & Male & $30-39$ & 33.9 & White & Yes & $\begin{array}{l}\text { Post- } \\
\text { graduate }\end{array}$ & $790-1,300$ & Yes & Married \\
\hline P10 & Female & $40-49$ & 44.1 & White & Yes & $\begin{array}{l}\text { High } \\
\text { School }\end{array}$ & $265-529$ & Yes & Married \\
\hline P11 & Female & $40-49$ & 41.2 & Black & No & $\begin{array}{l}\text { High } \\
\text { School }\end{array}$ & $\begin{array}{l}1000- \\
2000\end{array}$ & Yes & Married \\
\hline P12 & Female & $60-69$ & 44.9 & White & Yes & University & $\begin{array}{l}2001- \\
3000\end{array}$ & Yes & Divorced \\
\hline P13 & Female & $30-39$ & 27.6 & Black & No & College & $\begin{array}{l}2001- \\
3000\end{array}$ & No & Married \\
\hline P14 & Female & $40-49$ & 47.3 & White & Yes & University & $\begin{array}{l}2001- \\
3000\end{array}$ & Yes & Divorced \\
\hline P15 & Female & $50-59$ & 32.6 & White & Yes & $\begin{array}{l}\text { Post } \\
\text { graduate }\end{array}$ & $\begin{array}{l}2001- \\
3000\end{array}$ & Yes & Single \\
\hline
\end{tabular}

Findings

The barriers and facilitators were classified into three key themes and 10 sub-themes: (1) Lifestyle, (2) motivation and (3) education. 
Theme 1: Lifestyle

Accessibility to an unhealthy lifestyle

All participants expressed that an unhealthy lifestyle which includes physical inactivity and unhealthy eating habits is easily accessible. High financial costs of a healthy lifestyle were expressed as a barrier by most participants, resulting in unhealthy lifestyle habits.

"it is expensive to be on a diet in Brazil. It is very expensive..... It is cheaper to eat junk food.... becoming fat is cheap in Brazil; losing weight is expensive." (P8)

"I think that many people consider going to the gym, but think this is not affordable" (P1)

Exercising outdoors could be a solution to the expensive cost of gyms; however, the lack of safety in exercising outdoors such as encountering dangerous people and avoiding the sun and heat was described as a barrier.

"When people say "if they can't afford to go to the gym, they should do it outdoors". And I tried that, it is dangerous. If you are going to exercise, you have to do it before 7 am because of the sun, or at the end of the afternoon, when the sun goes down. Both are dangerous because you might encounter dangerous people on the way." (P13)

Most participants expressed that obesity and obesity-related illnesses are a barrier to exercise and therefore contribute to an unhealthy lifestyle. Difficulties in exercising included fatigue after a small amount of exercise and the health consequences of obesity such as joint pain.

“being heavy like I am, I don't have the physique to move really fast, to do physical activities more frequently... Why? Because I can't walk a lot, because my knees hurt" (P10)

Most participants described the easy accessibility of unhealthy food, including ready-meals, junk and processed food that are offered in the supermarkets and advertisements. One participant suggested that adverts for unhealthy food should be prohibited.

'"Ready-meals, 'it tastes like homemade food. Your mom's food.' You see it, it is there on the advertisements....... Just as the cigarette advertisements were prohibited.... we shouldn't have alcoholic beverages, sodas, chips, and junk food advertisements." (P8)

Time management

Participants described the lack of time and rush of daily routine and occupation preventing the preparation of healthy meals and exercise, attributing to an unhealthy lifestyle.

"maybe this rush, lack of quality of life, you have to run from one job to another and it's difficult to find the time to exercise, maybe this contributes as a barrier." (P9)

Three participants discussed time-management as a facilitator to a healthier lifestyle and weight loss. One method to improve eating habits was the use of alarms on their smartphone as a reminder to eat at regular intervals.

"I started to set an alarm on my cell phone because in the place where I work, we are always in a hurry so I don't stop.... I do the work and I end up forgetting to eat." (P2)

Facilitators to a healthy lifestyle

The participants discussed their experiences with facilitators to a healthy lifestyle for weight loss, which included changing eating habits such as preparing healthier meals, eating at regular intervals, eating smaller portions and chewing slowly. One 
participant explained the importance of gradually changing eating habits as extreme changes such as completely restricting certain foods could lead to cravings, and consequently weight regain.

“don't restrict everything...... because if you restrict something you like a lot, you will follow it for some time, but not for a long time, because you can't continue without it and you will want to eat it double." (P14)

Packed meals prepared at home have been described as a facilitator to weight loss and a healthier lifestyle. It also prevents social exclusion caused by patients avoiding social gatherings due to the temptation of unhealthy food. However, it has been described as something that requires more effort and time and may not be considered important for young people.

"I went out with my friends. We even went to a pizza place, but I took my packed snack." (P8)

“when you are 15/16 years old, you just don't think about packing your food and take it to your workplace. Today, I see that I could have done it" (P1)

Sleep quality has been described as a lifestyle factor that affects weight loss and is linked to mental health conditions such as anxiety. Good sleep quality can improve energy levels needed for exercise, preparing healthy meals and healthy eating habits.

"It (controlling anxiety) improves the quality of sleep. Now, I'm not hungry, you eat without being hungry...any kind of food. So, when I'm fine, I don't seek something to eat, I have a better night sleep, I can rest, I wake up feeling more willing." (P15)

One participant suggested using abandoned plots as local gardens to cultivate fruit and vegetables that could be sold within the community at a low price to promote healthy eating habits.

"having public gardens to cultivate food, that would be cheaper because this is expensive..... the city could sponsor the producers, the neighbourhood..... so we can have a garden and sell things for the residents for a symbolic price. So, every day you go there and there is lettuce, tomato, eggplant, pepper...." (P8)

One participant described the benefit of documenting eating habits with a food diary as a facilitator to lose weight.

"I started keeping a diary with what I eat every three hours, so I can see: "Wow...It has been four hours since the last time I ate." Because you go there to register the time and you see the last time you ate.... I started feeling less hungry after I started doing this because now I'm not eating when I'm hungry" (P1)

Theme 2: Motivation

Consequences of obesity

All participants described the consequences of obesity as disadvantages which increased motivation for weight loss. These included the personal and social consequences such as restricted choice in clothes, the impact on relationships, professional life, social activities and feeling excluded from society, for example the challenges in taking public transport.

"Many disadvantages: mobility difficulties...it leads you to joint pain difficulties, travelling difficulties because on the airplane, you face difficulties with the seat belt, passing through the bus turnstile. There are many difficulties for the ones who are overweight." (P8)

Comorbidities were a significant consequence of obesity described by all participants as a motivator to lose weight to improve their quality of life with fewer health issues, medication, struggles in daily activities and a future with their family. Musculoskeletal pain commonly affected the participants' daily lives.

"I had inflammation on my foot due to my weight which was terrible, a horrible pain, and since we need our feet for everything, even for getting up, I said: 'This can't continue'. That's what made me say: 'Now it is all or nothing."' (P11)

Other participants were unwilling to be medicine dependent due to their comorbidities, which motivated them to lose weight. 
Many participants used anti-obesity medication; however, they described them as ineffective in the long term since weight regain is common once the medication is stopped, discouraging their progress.

"they had results. But all the diets that I have done were based on medication. So, when I stopped taking the meds, the obesity came back, sometimes even double of what it was before." (P10)

Some participants described their prior experiences of negative side effects from anti-obesity medication; such was a motivation to seek alternative weight loss treatment.

"you become a hostage to them and they are very harmful, like, I took drugs to lose weight for many years and after some time I started having memory loss, even today, sometimes I don't remember something, I can't memorise words, insomnia, and also stress, it's a drug that affects the nervous system, so you have to take other drugs to feel calmer. It's like a bomb in your body, so after some time you don't want that anymore, because you realise it's very harmful." (P11)

Lifelong commitment

Participants emphasised that acceptance of a lifelong commitment to a change in habits is crucial to maintain weight loss. Some participants explained that a lack of commitment to habit and lifestyle change is a barrier to weight loss.

"you want to lose (weight), but you don't want to let go of many habits and that messes with you so badly" (P11)

Some participants explained that successful weight loss could result in complacency and belief that they will not regain the weight. This consequently causes a loss in commitment to a healthier lifestyle.

"It's a joy at first, but then you say: "I lost weight, it's good", then you start gaining weight again, because you relax thinking "I did it, so I can do it again", and you end up relaxing." (P14)

Participants explained that bariatric surgery is not the final solution to treat obesity, but rather the first step to weight loss and requires a commitment to attend follow-up appointments and follow a healthy lifestyle after surgery.

"All of them had the same point of view that the surgery was the first step because it is not the last step, it is the first one to lose weight." (P8)

Mental health

The relationship between mental health and weight loss was described as a barrier by most participants. They explained that conditions such as anxiety or depression could cause excessive eating, preventing weight loss.

"I think it is the compulsivity and anxiety. Every time I was nervous, I wanted to eat a sweet, so if I had something to do that demanded responsibility, a deadline, I couldn't keep up with my diet..... Also, family issues. All the sadness, all the anguish also affected me. It was something that prevented me from eating properly" (P12)

Some participants explained that obesity lowered self-esteem which consequently becomes a barrier to weight loss as patients are less motivated to lose weight or are too self-conscious to exercise in the gym.

"When you are overweight, your self-esteem gets low and you are like: 'You are overweight.' You think that you are going to the gym and people are going to stare at you. This is something that has blocked me from doing something I like." (P1)

Some participants explained that weight loss is a psychological process; it is crucial for the mind to change to see a physical change in weight loss.

“My experience is a more psychological process than physical.....The figure changes, but the mind changes even more. If the mind doesn't change, the body doesn't either." (P8) 
This psychological process aided by a psychologist can treat any psychological or emotional conditions and lead to strong will power which was emphasised as an important facilitator to remain motivated to weight loss and to overcome the battle that patients face with the temptation to break their diet.

"it doesn't matter what is going on around you because you made a commitment. This is when the psychologist acts. They help us to know ourselves, realise how important we are." (P7)

Support

All participants described the importance of support from family and social relations to lose weight. One participant described: "family support, my spouse, for me, was important... my friends, at work, everybody encouraged me." (P8) Despite this support, participants described the social environment as a barrier to weight loss. For example, not all household members will decide to follow a diet, so two different meals are prepared in the house.

"I think that the greatest difficulty is when people that live with you don't have the same goal. It is difficult for a person to prepare something just for you..... I think this is the barrier in obesity." (P1)

Healthcare professionals also offer support. Participants described the multidisciplinary approach to weight loss counselling as a facilitator, including doctors encouraging weight loss and psychologists and nutritionists providing guidance and follow-up appointments. This multidisciplinary approach is provided in weight loss programs which most participants have participated in and described as a facilitator to weight loss.

"The psychologist helps, the psychiatrist clarifies, the nutritionist guides you, helps and shows you the way, so putting all of this together, you have the strength, the will to lose weight. I think that is more complete." (P11)

However, one participant expressed their doubts in whether healthcare professionals understood the struggles that obese patients face with weight loss which can lead to their words of encouragement being interpreted as criticism rather than motivation.

“Most professionals see it this way, as laziness: 'You don't do it, because you like to stay lying down all day doing nothing.'...... So, your success so far was lost, because the person judges you as lazy, like you didn't try hard enough, so I think this is the worst part for the person who is really trying, not seeing any results at that moment and is criticised." (P14)

Some participants have described the lack of certain healthcare professionals such as nutritionists in the public healthcare system, which participants emphasised were crucial to facilitating the weight loss process.

"The Public Healthcare System doesn't have a nutritionist in all of its health care centres. There isn't someone to help the population." (P13)

Barriers to accessing bariatric surgery in the Sistema Único de Saúde- public funded health system (SUS) are the lengthy referral time, the criteria to access it and that many people within the population are unaware that it is available in the SUS.

"Today, a lot of people don't know that they have it on SUS..... but it already involves a lot of bureaucracy just to get that referral and it takes a lot of time. I don't think it is something that happens quickly." (P4)

Financial support is also an important facilitator to lose weight, for example, to access weight loss treatments such as a weight loss program or bariatric surgery through the private health insurance, since participants perceived it to be less accessible through the SUS.

"The financial aspect...I think that it is critical for the ones who want to lose weight..... My healthcare insurance covered everything. What about those who don't have it? This surgery costs R\$50,000 (US\$13,000) in Brazil, considering doctors, hospital, it is $\mathrm{R} \$ 50,000$ (US\$13,000)." (P8) 
Some participants suggested that more support from the government is a potential facilitator to weight loss, for example, providing exercise facilities for those that cannot afford it.

"Offer to the ones that can't afford swimming classes, gyms. Not everything should depend on the people's income. So, I think that the city should think about it." (P12)

\section{Theme 3: Education}

\section{Education is a facilitator}

Education on obesity includes information on weight loss methods, consequences of obesity and benefits of weight loss, which provides knowledge and encouragement to facilitate weight loss.

"I think education is important...... we start studying, reading, studying about diabetes, diseases that are associated to obesity. This encourages you to come out of that danger zone." (P8)

A lack of education on weight loss methods can result in a long period of unsuccessful weight loss.

"It took me more than ten years to realise what is really necessary to lose weight" (P11)

Some participants described the lack of awareness of the health consequences of obesity in the population, resulting in a complacent attitude towards obesity.

"I think people should be more aware of obesity because sometimes people think they are fat and that it is harmless there won't be any problems in the future." (P1)

The participants discussed several education methods. Three participants attended lectures on obesity and weight loss. These lectures were conducted by healthcare professionals and other patients who have experienced weight loss (expert patients). The healthcare professionals provided guidance about weight loss methods and health consequences of obesity and expert patients shared their experiences to be used as an example to others.

"I told him that I was interested in doing bariatric surgery because of the talks I had seen him do...... they (expert patients) said how they lost weight and how much weight they lost. And there are doctors there too, they answer our questions." (P4)

Expert patients were described as a beneficial education method by many participants as they can visualise the weight loss transformation, either from looking at picture evidence or watching them through the process. They can also learn about the benefits the expert patients have experienced from weight loss which inspires the patients to lose weight.

"There is a lady who works in the same place I do. She used to be way fatter than I am, and she had the surgery with the same doctor that I am going to have. And, today, she is really thin, her health is good, she stopped taking all her blood pressure medication, and now she just needs to maintain the surgery, with meds and all.... that helped me. You know? It motivated me because she is a living example. I saw something that was worthwhile... I got inspired." (P10)

Accessibility to weight loss information

Participants discussed that weight loss information should be easily accessible, with the internet being highlighted as an important facilitator to accessing information. Most participants accessed weight loss information from expert patients through social and professional relations, so participants suggested that the experiences of expert patients are shared on the internet and used as the main source of information.

"a video in which you talk about your experience, what you have done, your before and after. 'My life was like this.' Make a video to explain it. In social media, Facebook, Instagram. Today I think this is what people are looking for..... a person who has gone through that to tell their story." (P1) 
All participants had accessed obesity and weight loss information through the media: "Magazines, internet, e-mails about diets, weight loss, also on Facebook." (P2 ) and described them as facilitators. However, some participants believed that these sources through the media are less reliable and that the most reliable information is through the health system. One participant suggested the provision of social assistance by a healthcare professional for guidance on weight loss.

"I think it would be ideal to be inside the health system.... Because, for example, for me to get where I am today, I went after it because of my health, that was when the doctor said I had to take care of myself, 'you need to lose weight.' So, inside a health centre today, or social assistance" (P4)

One participant found weight loss education provided at the workplace beneficial for the weight loss process.

"I go to a lot of lectures at my job, you know? So, they talk about diabetes, about nutrition, many types of lectures." (P11)

Quality of information

The participants discussed the importance of the quality of information provided at both the individual and societal level. Inaccurate information can result in avoidance of specific beneficial weight loss treatments such as bariatric surgery due to either the patient's or the family's concern.

“I had never thought about bariatric surgery, I used to say: 'No way that I'm going to undergo such a risky surgery', because the information I had was that some people ended up with mental problems, people who didn't follow the instructions and got sick, etc., so I didn't have factual information about what bariatric surgery was." (P11)

Therefore, it is crucial to target these myths about weight loss methods and surgery by providing good quality and accurate information in weight loss education.

(Researcher): "What would work to promote weight loss?"

"I think information, but factual information" (P11)

\section{Discussion}

\section{Barriers}

Weight loss and maintenance rely on lifestyle factors such as healthy eating and exercise. Participants described this as less accessible due to the expensive cost of healthy food and gyms in Brazil, supporting the findings from Palmeira et al. (31,39). The Brazilian government made commitments to the "United Nations Decade of Action on Nutrition 2016-2025" which included a policy to reduce the tax on fresh foods and provide cash transfers to low-income families to buy fresh produce (40). These commitments were to be achieved by 2019; however, most of the participants of the study (which was conducted in February 2019) still believed that healthy food was more expensive than junk food. However, two participants viewed healthy food as affordable and believed it was rather the time and effort required to prepare healthy meals that were the barriers. Most participants agreed that time restrictions due to occupation and daily routine were a barrier to preparing healthy meals and exercising, supporting previous literature $(31,39,41)$.

The Brazilian government launched a strategic plan in 2011 to reduce NCDs which involved promoting physical activity through building public spaces for physical and leisure activities, building healthy urban spaces such as sidewalks, cycle paths and parks and creating violence prevention policies (42). The participants acknowledged the availability of these outdoor facilities; however, they explained that avoidance of the sun and the risk of violence in the street were barriers to using them. The fear of urban violence as a barrier to exercise in Brazil has been reported previously (41). This suggests the need for a review of the violence prevention policies, provision of shade in outdoor facilities and increased awareness of indoor public leisure facilities. Participants also revealed that obesity itself and obesity-related illnesses can be another barrier to exercise, supporting the findings in Palmeira et al. (31). 
Brazil has successfully decreased cigarette smoking among the population following increased advertisement bans, taxation, health warnings and treatment and support $(43,44)$. One participant suggested that this public health example should be followed to decrease junk food consumption, particularly prohibition of junk food advertisements in supermarkets and on the television. Dubois et al. showed that banning the advertising of potato chips in the UK market can reduce the quantity sold by $10 \%$ (45). The WHO recommends that an advertising ban should reduce exposure to the marketing of foods high in saturated fats, trans-fatty acids, salt or free sugars (46).

An important finding was that weight loss treatment through the SUS is perceived to be less accessible due to lack of awareness of available treatments, longer referral periods, stringent criteria for surgery and a lack of staff such as nutritionists, who participants have found very useful in the weight loss process. These reasons led patients in the study to access weight loss treatment privately, available through employee benefits or out-of-pocket. Only one-quarter of the Brazilian population access private health insurance, meaning the majority of the population have reduced access to weight loss treatment (47).

The current study identified doubt in the success of treatment and fear of mental health problems and death following surgery as barriers to accessing treatment. This suggests the increased influence of inaccurate information and weight loss myths in Brazil on decision making of treatment and the need of accurate information dissemination. Participants identified the health system or health professionals as reliable sources of information, providing accurate information to achieve successful weight loss, consistent with the literature $(48,49)$. One participant suggested increasing the promotion of weight loss techniques through social assistance by healthcare professionals. This could be provided through community health workers promoting a healthy lifestyle during home visits (50).

Unfortunately, potential harmful consequences of diets have been reported in the literature such as hunger, depressed mood, irritability, decreased sociability and binge eating which can eventually develop into bulimia nervosa (51-53). Additionally, antiobesity medication can produce side-effects such as faecal incontinence, diarrhoea, flatulence and dyspepsia (54-57). The most commonly used anti-obesity medications in Brazil are orlistat and sibutramine, with most participants mentioning the use of sibutramine, which is not available in the European and US markets due to its association with increased risk of cardiovascular events and strokes (58-60). Participants in this study reported some of the side effects described in the literature as a barrier. This highlights the importance of safety netting to ensure patients understand safe weight loss methods and side effects of treatment.

Mental health conditions are linked to obesity and can influence weight loss and weight gain $(61,62)$. Additionally, mental health conditions such as depression are linked to reduced quality of sleep which some participants identified as a barrier to weight loss (63). This is supported by further literature, reporting that sleep deprivation can increase food intake and appetite (64). These findings emphasise the importance of psychological treatment and change in mind-set before commencing weight loss treatment and the crucial role of the psychologist in the multidisciplinary approach to weight loss. This can increase self-esteem and will-power which participants identified as important facilitators. The literature have reported that the multidisciplinary approach, involving the psychologist and nutritionist and regular follow-up consultations are effective in facilitating weight loss, improving post-operative outcomes and maintaining motivation (65-67). Therefore, healthcare professionals should encourage and remind patients to attend these crucial follow-up appointments and maintain a good relationship with patients by ensuring words of encouragement or guidance are not misinterpreted as criticism by patients.

\section{Facilitators}

Eating habits such as consumption of healthy food, eating at regular intervals and chewing slowly are important for weight loss (39). Participants reported that this is facilitated by the gradual change in eating habits to prevent cravings and relapse to unhealthy eating habits. This supports previous findings that the inclusion of a small portion of a sweet snack can facilitate diet control (68). A change in eating habits can lead to social isolation due to avoidance of temptations of unhealthy food at social gatherings (39). Some participants identified the preparation of a packed meal at home to take to work or social gatherings as a facilitator to diet control and prevents social exclusion. Documenting eating habits is an accurate method to examine eating habits and participants identified it as a facilitator to weight loss, allowing for reflection and progression of lifestyle changes (69). Setting alarms as reminders to eat at regular intervals is another facilitator described by participants.

Page 12/18 
A cooperative food network consisting of local gardens to cultivate fruit and vegetables to be sold within the community at affordable prices was a suggestion made by one participant to facilitate a healthy lifestyle. These cooperative food systems aim to supply fresh and healthy food locally, keep money in the community and celebrate good food, culture and community. An example of a cooperative food network is the "Local Organic Food Co-ops Network" in Ontario, Canada which is a non-profit organisation (70). Following this example, strong leadership, education, training and information and cooperation among cooperatives, including financial support are essential factors for the success of a network and need to be considered if the initiative is done in Brazil.

To overcome the barriers, access to social capital is a crucial facilitator for weight loss motivation (71). However, participants described opposing diets and goals within the household and social environment as a barrier to weight loss, increasing temptation and lack of commitment to a healthy lifestyle, supporting previous literature $(31,39)$. Venturini discussed that families should perceive themselves as an integral part to the weight loss process and eating habits should change for the whole family; thus, education to family members on their role in weight loss support is required (72).

An interesting finding of the study that has not previously been reported is the huge impact of expert patients in inspiring and motivating patients to lose weight. Expert patients allowed for visualisation of the weight loss changes, either through pictures or in real life, and learning about the health, physical and social improvements experienced as well as the opportunity for questions to be answered. Shared social identity between obese patients is a facilitator to weight loss through sharing information, problems and celebrating patients' successes (73). The current study suggests that these beneficial live examples should be used for health promotion, for example on the internet or TV channels as well as through the health system and weight loss programs.

Future implications

These findings may inform the development of further approaches to facilitate weight loss in individuals. For example, the mixed views on the cost of healthy food demonstrate the need for education on financially accessible healthy meals. The Brazilian government have published dietary guidelines for the population, including healthy meal options (74). These should be made easily accessible, comprehensive and concise for the public. Prohibition of junk food advertisements in Brazil and improving affordability and safety of exercise facilities should be considered. Cooperative food networks using abandoned plots to cultivate fruit and vegetables which can be sold within the community, following the example in Ontario should be considered. Increased education providing accurate information is required to avoid harmful and unsuccessful weight loss attempts. Information provided should feature previous patients' examples, including the benefits of using a weight loss program with a multidisciplinary team, use of a food diary to control diets and time-management skills such as setting an alarm for mealtimes. The multidisciplinary approach to weight loss is essential, and a good relationship between healthcare professionals and patients is crucial to maintain trust and motivation for weight loss. In addition, local governments should continue to improve the environment and opportunities for physical activity to create healthy, active cities recommended by the WHO, in particular the violence prevention policies and providing shade as identified in the study $(42,75)$. Future research should assess the effectiveness of education methods, particularly the use of expert patients and the quality of weight loss education and information in Brazil.

Limitations

The study has some limitations. This was cross-language qualitative research with the use of interpreters. Qualitative thematic analysis relies on deriving meaning from words and data, and some meanings may be lost in translation from Brazilian Portuguese to English leading to bias of misinterpretation $(37,76)$. Measures were taken to minimise this by a second interpreter reviewing the accuracy of translations and the use of redacted translation, meaning timings of the audio-recording being documented at regular intervals on the transcripts to allow for clarification if required. Due to lack of availability of one single interpreter, three interpreters were used during the interviews. To avoid potential inconsistencies in data collection, CM was present during all the interviews and practised and briefed the interpreters on asking questions. The use of a local interpreter provided benefits as they could explain cultural contexts to the researcher and provide insight into the meaning of responses. The BMI of CM and the interpreters were normal which may lead to social desirability bias (7). The normal BMI of the researcher 
may also affect the analysis and interpretation of the study; however, the primary researcher took a reflexive approach during the study and analysis triangulation was conducted to minimise this.

More women (12) participated in the study than men (3); however, this may be due to the higher proportion of women who are obese and the higher proportion of women seeking healthcare compared to men in Brazil, meaning the range of views may be limited $(2,77)$. Moreover, the participants were recruited from a private health clinic, with only one participant from the lowest range of monthly household income and none from the highest, meaning the range of views and experiences may be limited. Therefore, future studies should include more views from the highest and lowest household incomes, as this study highlighted the importance of financial situation with weight loss and obesity is growing among the lowest socioeconomic group in Southeast Brazil (78).

\section{Conclusion}

This study explored the barriers and facilitators to weight loss in overweight and obese adults in Southeast Brazil, contributing to the existing literature. Barriers to a healthy lifestyle such as financial difficulties, time, junk food advertising and participants' perceived lack of opportunity for safe outdoor exercise need to be addressed. Education was highlighted as an important facilitator and can be used to challenge these barriers and dispel myths on weight loss treatment, with expert patients being described as the most beneficial education method. At the individual level, successful weight loss requires a lifelong commitment, motivation and support from a multidisciplinary team, family and friends. At a societal level, removing the barriers and promoting the facilitators have the potential to achieve successful weight loss and a reduction in obesity rates in Brazil, improving health, social and economic consequences of the disease.

\section{Abbreviations}

\section{$\mathrm{BMI}$}

Body Mass Index

NCD

Non-Communicable Disease

SUS

Sistema Único de Saúde

WHO

World Health Organisation

\section{Declarations}

\section{Ethics approval and consent to participate}

The research was approved by the BMedSc Population Sciences and Humanities Internal Ethics Review Committee at the University of Birmingham, Scientific Committee and Ethics Committee at Instituto Lauro de Souza Lima. All participants signed an informed consent form before the interviews.

\section{Consent for publication}

The participants signed an informed consent form which included consent for the publication of data.

\section{Availability of data and material}

The datasets used and analysed during the current study are available from the corresponding author on reasonable request.

\section{Competing interests}

The authors declare that they have no competing interests. 


\section{Funding}

The University of Birmingham BMedSc program provided funding for the expenses of the study. The University of Birmingham had no role in the design, collection, analysis and interpretation of data in the study.

\section{Authors' contributions}

$\mathrm{CM}$ conceived the study question, designed the study, conducted interviews and data analysis and wrote and revised the manuscript. GdW helped to conceive the study question, research plan, provided global and national health and socio-economic contexts and reviewed drafts. MV helped to design the study, provide local context on the study question and helped with data collection. RR helped in the study design, provided guidance on data analysis and reviewed drafts. NT helped with analysis by conducting analysis triangulation. RP helped with the study design and data collection. All authors read and approved the final manuscript.

\section{Acknowledgements}

The interpreters providing crucial help in translation of the interviews and transcripts from Brazilian Portuguese to English, the multidisciplinary team at the health center helped in the recruitment of participants.

\section{References}

1. World Health Organization. Obesity and overweight [Internet]. 2018 [cited 2018 Nov 30]. Available from: http://www.who.int/news-room/fact-sheets/detail/obesity-and-overweight

2. World Health Organization. Diabetes Country Profiles: Brazil [Internet]. 2016 [cited 2018 Nov 30]. Available from: http://www.who.int/diabetes/country-profiles/bra_en.pdf

3. Malta DC, Andrade SC, Claro RM, Bernal RTI, Monteiro CA. Trends in prevalence of overweight and obesity in adults in 26 Brazilian state capitals and the Federal District from 2006 to 2012. Rev Bras Epidemiol. 2014;17(1):267-76.

4. Ramos AC. Brazil looking for completing his space in bariatric surgery. ABCD Arq Bras Cir Dig (São Paulo). 2014;27:1-1.

5. Angrisani L, Santonicola A, lovino P, Formisano G, Buchwald H, Scopinaro N. Bariatric Surgery Worldwide 2013. Obes Surg. 2015;25(10):1822-32.

6. Monteiro CA, Conde WL, Popkin BM. Income-specific trends in obesity in Brazil: 1975-2003. Am J Public Health. 2007;97(10):1808-12.

7. World Health Organisation. Physical status: the use and interpretation of anthropometry. World Health Organization technical report series. 1995.

8. Guh DP, Zhang W, Bansback N, Amarsi Z, Birmingham CL, Anis AH. The incidence of co-morbidities related to obesity and overweight: A systematic review and meta-analysis. BMC Public Health. 2009;9:88.

9. CDC in Brazil Centers for Disease Control and Prevention Center for Global Health [Internet]. 2016 [cited 2018 Nov 30]. Available from: http://viz.healthmetricsandevaluation.org/g

10. World Health Organization. Non-communicable diseases Country Profiles. 2018 [cited 2018 Nov 30]; Available from: https://www.who.int/nmh/countries/bra_en.pdf

11. Ribeiro ALP, Duncan BB, Brant LCC, Lotufo PA, Mill JG, Barreto SM. Cardiovascular Health in Brazil Trends and Perspectives. Circulation. 2016;133(4):422-33.

12. Schwartz MB, Brownell KD. Obesity and body image. Body Image. 2004;1(1):43-56.

13. Silva DAS, Nahas MV, de Sousa TF, Del Duca GF, Peres KG. Prevalence and associated factors with body image dissatisfaction among adults in southern Brazil: A population-based study. Body Image. 2011;8(4):427-31.

14. Santana MLP, Silva RDCR, Assis AMO, Raich RM, Machado MEPC, de J Pinto E, et al. Factors associated with body image dissatisfaction among adolescents in public schools students in Salvador, Brazil. Nutr Hosp. 2013;28(3):747-55. 
15. Klein S, Burke LE, Bray GA, Blair S, Allison DB, Pi-Sunyer X, et al. Clinical implications of obesity with specific focus on cardiovascular disease: A statement for professionals from the American Heart Association Council on Nutrition, Physical Activity, and Metabolism. Circulation. 2004;110(18):2952-67.

16. Wing RR, Lang W, Wadden TA, Safford M, Knowler WC, Bertoni AG, et al. Benefits of modest weight loss in improving cardiovascular risk factors in overweight and obese individuals with type 2 diabetes. Diabetes Care. 2011;34(7):1481-6.

17. Dobbs R, Sawyers C, Thompson F, Manyika J, Woetzel J, Child P, et al. Overcoming obesity: An initial economic analysis. McKinsey Global Institute. 2014.

18. Rtveladze K, Marsh T, Webber L, Kilpi F, Levy D, Conde W, et al. Health and Economic Burden of Obesity in Brazil. PLoS One. 2013;8(7):e68785.

19. Sacks FM, Bray GA, Carey VJ, Smith SR, Ryan DH, Anton SD, et al. Comparison of weight-loss diets with different compositions of fat, protein, and carbohydrates. N Engl J Med. 2009;360(9):859-73.

20. Foster GD, Wyatt HR, Hill JO, Makris AP, Rosenbaum DL, Brill C, et al. Weight and metabolic outcomes after 2 years on a lowcarbohydrate versus low-fat diet: A randomized trial. Ann Intern Med. 2010;153(3):147-57.

21. Appel LJ, Clark JM, Yeh H-C, Wang N-Y, Coughlin JW, Daumit G, et al. Comparative Effectiveness of Weight-Loss Interventions in Clinical Practice. N Engl J Med. 2011;365(21):1959-68.

22. Donnelly JE, Blair SN, Jakicic JM, Manore MM, Rankin JW, Smith BK. Appropriate physical activity intervention strategies for weight loss and prevention of weight regain for adults. Med Sci Sports Exerc. 2009;41(2):459-71.

23. Haskell WL, Lee IM, Pate RR, Powell KE, Blair SN, Franklin BA, et al. Physical activity and public health: Updated recommendation for adults from the American College of Sports Medicine and the American Heart Association. circ. 2007;116(9):1081.

24. Swift DL, Johannsen NM, Lavie CJ, Earnest CP, Church TS. The role of exercise and physical activity in weight loss and maintenance. Prog Cardiovasc Dis. 2014;56(4):441-7.

25. Neovius M, Johansson K, Rössner S. Head-to-head studies evaluating efficacy of pharmaco-therapy for obesity: A systematic review and meta-analysis. Obes Rev. 2008;9(5):420-7.

26. Maggard MA, Shugarman LR, Suttorp M, Maglione M, Sugarman HJ, Livingston EH, et al. Meta-analysis: Surgical treatment of obesity. Ann Intern Med. 2005;142(7):547-59.

27. Karlsson J, Taft C, Rydén A, Sjöström L, Sullivan M. Ten-year trends in health-related quality of life after surgical and conventional treatment for severe obesity: The SOS intervention study. Int J Obes. 2007;31(8):1248.

28. Colquitt JL, Pickett K, Loveman E, Frampton GK. Surgery for weight loss in adults. Cochrane Database Syst Rev [Internet]. 2014 Aug 8 [cited 2019 May 1];(8). Available from: http://doi.wiley.com/10.1002/14651858.CD003641.pub4

29. Feigenbaum A, Pasternak S, Zusk E, Sarid M, Vinker S. Influence of intense multidisciplinary follow-up and orlistat on weight reduction in a primary care setting. BMC Fam Pract. 2005;6(1):5.

30. Jaime PC, da Silva ACF, Gentil PC, Claro RM, Monteiro CA. Brazilian obesity prevention and control initiatives. Obes Rev. 2013;14(2):88-95.

31. Palmeira S, Garrido CM, Laine M, Resumo PS. Factors involved in adherence to obesity treatment. Cienc y enfermería. 2016;22(1):11-22.

32. Abrantes MM, Lamounier JA, Colosimo EA. Overweight and obesity prevalence in Northeast and Southeast Regions of Brazil. Rev Assoc Med Bras. 2003;49(2):162-6.

33. Porsse AA, Stampe MZ, Portugal MS, De Almeida ES. Demographic Change and Regional Economic Growth in Brazil [Internet]. University of Sao Paulo; 2012 [cited 2018 Nov 30]. Available from: http://www.usp.br/nereus/wpcontent/uploads/TDNereus_03_12.pdf

34. Fiess NM, Verner D. Migration in Brazil in the 1990s [Internet]. 2002 [cited 2018 Nov 30]. Available from: https://pdfs.semanticscholar.org/6bb6/71bb9c074c219ab9a88b3ceb9799933325c1.pdf

35. University of Birmingham. The University of Birmingham Data Protection Policy [Internet]. 2018 [cited 2019 May 4]. Available from: https://www.birmingham.ac.uk/Documents/university/legal/data-prot-policy.pdf 
36. Palmeira CS, Garrido LM, Silva M, Guimaraes A LM. Perceptions about the health condition of people with obesity. Rev da Rede Enferm do Nord [Internet]. 2013 [cited 2018 Nov 30];17(5):724-31. Available from: http://www.redalyc.org/articulo.oa? id $=324047801019$

37. Braun V, Clarke V. Using thematic analysis in psychology. Qual Res Psychol. 2006;3(2):77-101.

38. Tong A, Sainsbury P, Craig J. Consolidated criteria for reporting qualitative research (COREQ): A 32-item checklist for interviews and focus groups. Int J Qual Heal Care. 2007;19(6):349-57.

39. Oliveira A, Silva M. Factores que dificultam a perda de peso em mulheres obesas de graus I e II. Rev Psicol Saude. 2014;6(1):74-82.

40. World Health Organisation. Brazil first country to make specific commitments in UN Decade of Action on Nutrition. WHO [Internet]. 2017 [cited 2018 Nov 30]; Available from: http://www.who.int/nutrition/decade-of-action/brazil-commitment22may2017/en/

41. Morais E, Ferreira P, Correa E. Barreiras para a prática de exercício físico regular em indivíduos com fatores de risco cardiovascular. Saúde Coletiva,. 2010;7(45):282-7.

42. Malta DC, Morais Neto OL De, Silva Junior JB Da. Presentation of the Strategic Action Plan for Coping with Chronic Diseases in Brazil from 2011 to 2022. Epidemiol e Serviços Saúde. 2011;20(4):425-38.

43. Galduróz JCF, Fonseca AM, Noto AR, Carlini EA. Decrease in tobacco use among Brazilian students: A possible consequence of the ban on cigarette advertising? Addict Behav. 2007;32(6):1309-13.

44. Szklo AS, De Almeida LM, Figueiredo VC, Autran M, Malta D, Caixeta R, et al. A snapshot of the striking decrease in cigarette smoking prevalence in Brazil between 1989 and 2008. Prev Med (Baltim). 2012;54(2):162-7.

45. Dubois P, Griffith R, O'Connell M. The effects of banning advertising in junk food markets. Rev Econ Stud. 2018;85(1):396436.

46. World Health Organization. Set of Recommendations on the Marketing of Foods and Non-Alcoholoic Beverages to Childern. World Health Organisation. 2010.

47. Santos IS, Ugá MAD, Porto SM. The public-private mix in the Brazilian Health System: financing, delivery and utilization of health services. Cien Saude Colet. 2008;13(5):1431-40.

48. Galuska DA, Will JC, Serdula MK, Ford ES. Are health care professionals advising obese patients to lose weight? J Am Med Assoc. 1999;282(16):1576-8.

49. Ockene IS, Hebert JR, Ockene JK, Saperia GM, Stanek E, Nicolosi R, et al. Effect of physician-delivered nutrition counseling training and an office-support program on saturated fat intake, weight, and serum lipid measurements in a hyperlipidemic population: Worcester area trial for counseling in hyperlipidemia (WATCH). Arch Intern Med. 1999;159(7):725-31.

50. Macinko J, Harris MJ. Brazil's Family Health Strategy - Delivering Community-Based Primary Care in a Universal Health System. N Engl J Med. 2015;372(23):2177-81.

51. Keys A. The biology of human starvation. Am J Clin Nutr. 1978;31(2):197.

52. Franklin JC, Schiele BC, Brozek J, Keys A. Observations on human behavior in experimental semistarvation and rehabilitation. J Clin Psychol. 1948;4(1):28-45.

53. Yanovski SZ, Billington CJ, Epstein LH, Goodwin NJ, Hill JO, Pi-Sunyer FX, et al. Dieting and the development of eating disorders in overweight and obese adults. Arch Intern Med. 2000;160(17):2581-9.

54. MacDaniels JS, Schwartz TL. Effectiveness, tolerability and practical application of the newer generation anti-obesity medications. Drugs Context. 2016;5:212291.

55. loannides-Demos LL, Proietto J, Tonkin AM, McNeil JJ. Safety of drug therapies used for weight loss and treatment of obesity. Drug Saf. 2006;29(4):277-302.

56. Rucker D, Padwal R, Li SK, Curioni C, Lau DCW. Long term pharmacotherapy for obesity and overweight: Updated metaanalysis. Br Med J. 2007;335(7631):1194-9.

57. Padwal RS, Rucker D, Li SK, Curioni C, Lau DC. Long-term pharmacotherapy for obesity and overweight. Cochrane Database Syst Rev. 2004;(3):CD004094. 
58. de Carvalho MD, de Souza Filho MD, Moura FS, de Carvalho JD, Müller MC, Neves R V, et al. Use of anti-obesity drugs among college students. Rev Assoc Med Bras. 2011;57(5):558-64.

59. James WPT, Caterson ID, Coutinho W, Finer N, Van Gaal LF, Maggioni AP, et al. Effect of Sibutramine on Cardiovascular Outcomes in Overweight and Obese Subjects. N Engl J Med. 2010;363(10):905-17.

60. Kang JG, Park CY. Anti-obesity drugs: A review about their effects and safety. Diabetes Metab J. 2012;36(1):13-25.

61. Scott KM, McGee MA, Wells JE, Oakley Browne MA. Obesity and mental disorders in the adult general population. J Psychosom Res. 2008;64(1):97-105.

62. Janney CA, Greenberg JM, Moin T, Kim HM, Holleman RG, Hughes M, et al. Does mental health influence weight loss in adults with prediabetes? Findings from the VA Diabetes Prevention Program. Gen Hosp Psychiatry. 2018;53:32-7.

63. Zhang J, Paksarian D, Lamers F, Hickie IB, He J, Merikangas KR. Sleep Patterns and Mental Health Correlates in US Adolescents. J Pediatr. 2017;182:137-43.

64. St-Onge MP. Sleep-obesity relation: underlying mechanisms and consequences for treatment. Obes Rev. 2017;18:34-9.

65. Chaim EA, Pareja JC, Gestic MA, Utrini MP, Cazzo E. Preoperative multidisciplinary program for bariatric surgery: a proposal for the Brazilian Public Health System. Arq Gastroenterol. 2017;54(1):70-4.

66. Shen R, Dugay G, Rajaram K, Cabrera I, Siegel N, Ren CJ. Impact of patient follow-up on weight loss after bariatric surgery. Obes Surg. 2004;14(4):514-9.

67. Harper J, Madan AK, Ternovits CA, Tichansky DS. What happens to patients who do not follow-up after bariatric surgery? Am Surg. 2007;73(2):181-4.

68. Metzgar CJ, Preston AG, Miller DL, Nickols-Richardson SM. Facilitators and barriers to weight loss and weight loss maintenance: A qualitative exploration. J Hum Nutr Diet. 2015;28(6):593-603.

69. Margetts B, Nelson M. Assessment of food consumption and nutrient intake. In: Margetts BM, Nelson M, editors. Design concepts in nutritional epidemiology. New York: Oxford University Press; 1997. p. 123-69.

70. Sumner J, McMurtry JJ, Renglich H. Leveraging the Local: Cooperative Food Systems and the Local Organic Food Co-ops Network in Ontario, Canada. J Agric Food Syst Community Dev. 2014;4(3):47-60.

71. Liebl L, Barnason S, Brage Hudson D. Awakening: A qualitative study on maintaining weight loss after bariatric surgery. J Clin Nurs. 2016;25(7-8):951-61.

72. Venturini LP. Obesidade e familia: Uma caracterização de famílias de crianças obesas ea percepção dos familiares e das crianças de sua imagem corporal. Universidade de São Paulo; 2000.

73. Tarrant M, Khan SS, Farrow C V., Shah P, Daly M, Kos K. Patient experiences of a bariatric group programme for managing obesity: A qualitative interview study. Br J Health Psychol. 2017;22(1):77-93.

74. Ministry of Health of Brazil. Dietary guidelines for the Brazilian population. 2nd ed Bras Minist Heal Brazil. 2014;

75. Edwards P, Tsouros A. Promoting physical activity and active living in urban environments. World Health Organisation. 2006.

76. van Nes F, Abma T, Jonsson H, Deeg D. Language differences in qualitative research: Is meaning lost in translation? Eur $\mathrm{J}$ Ageing. 2010;7(4):313-6.

77. Pinheiro RS, Viacava F, Travassos C, Brito A dos S. Gender, morbidity, access and utilization of health services in Brazil. Cien Saude Colet. 2002;7(687-707).

78. Sawaya AL, Dallal G, Solymos G, de Sousa MH, Ventura ML, Roberts SB, et al. Obesity and Malnutrition in a Shantytown Population in the City of São Paulo, Brazil. Obes Res. 1995;3(2):107s-115s.

\section{Supplementary Files}

This is a list of supplementary files associated with this preprint. Click to download.

- COREQchecklist.docx

Page $18 / 18$ 